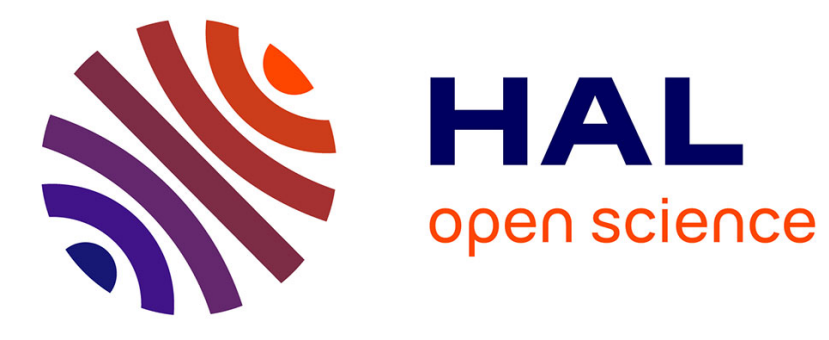

\title{
Borane-Catalysed Dinitrogen Borylation by 1,3-B-H Bond Addition
}

Anaïs Coffinet, Dan Zhang, Laure Vendier, Sébastien Bontemps, Antoine Simonneau

\section{- To cite this version:}

Anaïs Coffinet, Dan Zhang, Laure Vendier, Sébastien Bontemps, Antoine Simonneau. BoraneCatalysed Dinitrogen Borylation by 1,3-B-H Bond Addition. Dalton Transactions, 2021, 50 (16), pp.5582-5589. 10.1039/D1DT00317H . hal-03176261

\section{HAL Id: hal-03176261 https://hal.science/hal-03176261}

Submitted on 22 Mar 2021

HAL is a multi-disciplinary open access archive for the deposit and dissemination of scientific research documents, whether they are published or not. The documents may come from teaching and research institutions in France or abroad, or from public or private research centers.
L'archive ouverte pluridisciplinaire HAL, est destinée au dépôt et à la diffusion de documents scientifiques de niveau recherche, publiés ou non, émanant des établissements d'enseignement et de recherche français ou étrangers, des laboratoires publics ou privés. 


\title{
Borane-Catalysed Dinitrogen Borylation by 1,3-B-H Bond Addition
}

\author{
Anaïs Coffinet, Dan Zhang, Laure Vendier, Sébastien Bontemps and Antoine Simonneau*
}

The borylation of ligated dinitrogen by 1,3-B-H bond addition over a $\mathrm{M}-\mathrm{N} \equiv \mathrm{N}$ unit using various hydroboranes has been examined. In a previous study, we have shown that Piers' borane (1) reacted with the tungsten dinitrogen complex $\mathbf{2}$ to afford a boryldiazenido-hydrido-tungsten species. The ease and mildness of this reaction has pushed us to extend its scope, with the working hypothesis that 1 could potentially catalyse the 1,3-B-H bond addition of other hydroboranes. Under productive reaction conditions, dicyclohexylborane ( $\left.\mathrm{HBCy}_{2}\right)$ and diisopinocampheylborane ( $\mathrm{HBI}_{\left.\mathrm{B} \mathrm{C}_{2}\right)}$ ) underwent retro-hydroboration to give cyclohexylborane $\left(\mathrm{H}_{2} \mathrm{BCy}\right)$ or isopinocampheylborane $\left(\mathrm{H}_{2} \mathrm{Blpc}\right)$, respectively, these monoalkylboranes acting as $\mathrm{N}_{2}$-borylating agents in the presence of a catalytic amount of 1. Under similar conditions, 9-borabicyclononane (9-BBN) slowly adds over the $\mathrm{W}-\mathrm{N} \equiv \mathrm{N}$ unit without rearrangement to a monoalkylborane. Catecholborane (HBcat) performs the 1,3-B-H bond addition without the need of a catalyst. We were not able to build more than one covalent $\mathrm{B}-\mathrm{N}$ bond between the terminal $\mathrm{N}$ of the $\mathrm{N}_{2}$ ligand and the boron reagent with this methodology.

\section{Introduction}

The chemistry of dinitrogen complexes has attracted important research efforts over almost 60 years. ${ }^{1}$ Indeed, they can serve as platforms to transform the inert but abundant $\mathrm{N}_{2}$ molecule, and since the early 2000s several catalysts for the reduction of dinitrogen into ammonia ${ }^{2}$ under ambient temperature and pressure have been devised. This contrasts with the harsh conditions found in the Haber-Bosch plant, ${ }^{3}$ where $N_{2}$ is converted into ammonia by hydrogenolysis at the industrial level. $\mathrm{N}_{2}$ complexes can also serve as models for the active sites of the nitrogenases, ${ }^{4}$ the enzymes responsible for biological nitrogen fixation. Beyond ammonia and hydrazine, the quest for the direct conversion of dinitrogen into more complex nitrogencontaining compounds has fuelled interest towards the construction of $\mathrm{N}-\mathrm{E}$ bonds $(\mathrm{E}=\mathrm{C}, \mathrm{B}, \mathrm{Si}, \mathrm{Al}, \mathrm{Ga}$ ) at ligated dinitrogen. ${ }^{1 a}$ In this perspective, our team has reported $\mathrm{N}_{2}$ silylation and borylation methods inspired by the chemistry of the Frustrated Lewis Pairs. ${ }^{5}$ We have notably shown that in the presence of Piers' borane $\left.\left[\mathrm{HB}\left(\mathrm{C}_{6} \mathrm{~F}_{5}\right)_{2}, 1\right]\right]^{6}$ compound trans[W $\left(\mathrm{N}_{2}\right)_{2}$ (depe $\left.)_{2}\right]$ [2, depe $=1,2$-bis(diethylphosphino)ethane] underwent a formal 1,3-addition of the $\mathrm{B}-\mathrm{H}$ bond across the $\mathrm{W}-$ $\mathrm{N} \equiv \mathrm{N}$ unit $(\mathbf{2} \rightarrow \mathbf{3}$, Scheme 1$),{ }^{5 b}$ a complementary $\mathrm{N}_{2}$ borylation method to $1,3-\mathrm{B}-\mathrm{X}$ bond addition. ${ }^{7}$ The proposed mechanism to account for this transformation, based on experimental observations, involved two molecules of 1 , one being the $\mathrm{N}_{2}$ borylating agent, the other assuming the role of $\mathrm{B}-\mathrm{H}$ bond cleavage and hydride shuttling to the metal centre, thus closing a catalytic cycle (Scheme 1). As a continuation of this work, we wanted to check whether this 1,3-B-H addition can be extended to other hydroboranes and if Piers' borane would be a competent catalyst for this reaction. ${ }^{8}$

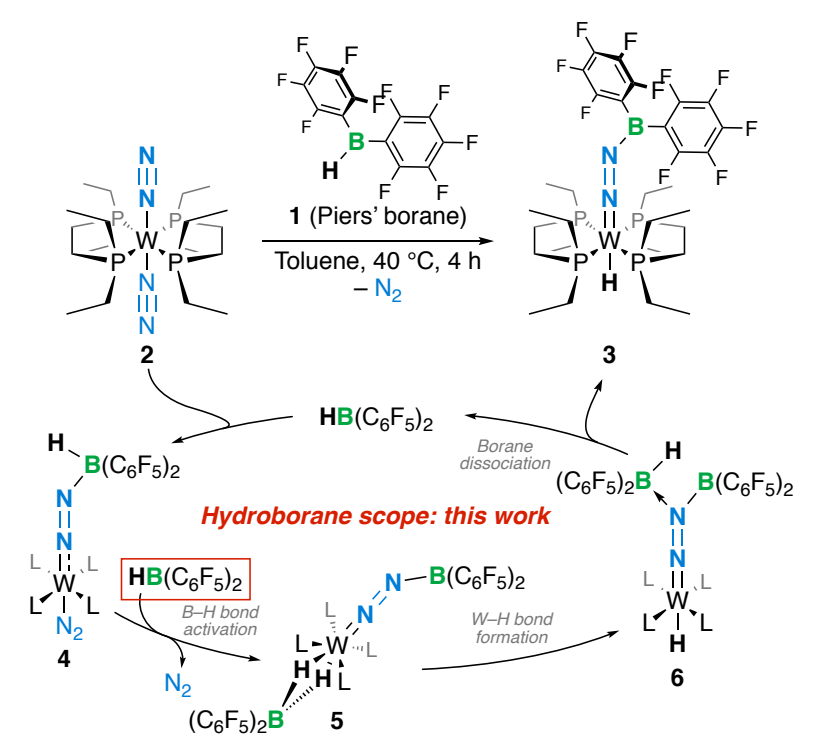
Scheme 1. Previously reported ${ }^{5 b} 1,3-B-H$ bond addition of Piers' borane $(\mathbf{1})$ on
dinitrogen complex 2 and the proposition of a borane-catalysed mechanism ( $L=1 / 2$ dinitro
depe).

\section{Results}

Four different organo-hydroboranes, namely dicyclohexylborane $\left(\mathrm{HBCy}_{2}\right)$, diisopinocampheylborane $\left(\mathrm{HBIpc}_{2}\right), 9-\mathrm{BBN}$ (9-borabicyclononane) and catecholborane (HBcat) were examined. Three types of reactivities have been observed, as detailed below.

Reactions of 2 with dicyclohexylborane $\left(\mathrm{HBCy}_{2}\right)$ and diisopinocampheylborane ( $\mathrm{HBIpc}_{2}$ )

We reacted trans-[W( $\left.\left(\mathrm{N}_{2}\right)_{2}(\text { depe })_{2}\right] 2$ with one equivalent of dicyclohexylborane $\left(\mathrm{HBC}_{2}\right)$ at room temperature in $\mathrm{C}_{6} \mathrm{D}_{6}$. NMR spectroscopy analysis revealed the absence of new tungsten species, and raising the temperature to $80^{\circ} \mathrm{C}$ overnight did not change this outcome. This contrasts with the reaction of $\mathbf{2}$ with the electrophilic hydroborane $\mathbf{1}$, occurring under milder conditions and during which the Lewis acid-base adduct thereof (4, Scheme 1) could be detected. ${ }^{5 b}{ }^{11} \mathrm{~B}$ NMR analysis revealed the presence tricyclohexyldiborane and $\mathrm{BCy}_{3}$ (see Fig. S1). This substituent scrambling presumably arose from a retrohydroboration, a reaction known for thexyl- and 
isopinocampheyl-substituted boranes, and readily occurs in the absence of 2 (Scheme 2, top and Fig. S1). ${ }^{9}$ To verify whether $\mathrm{HB}\left(\mathrm{C}_{6} \mathrm{~F}_{5}\right)_{2}(\mathbf{1})$ could catalyse $1,3-\mathrm{B}-\mathrm{H}$ bond addition of $\mathrm{HBCy}_{2}$ (or in-situ-formed $\mathrm{H}_{2} \mathrm{BCy}$ ), we repeated the experiment in the presence of $10 \mathrm{~mol} \%$ of 1 at $60{ }^{\circ} \mathrm{C}$ in $\mathrm{C}_{6} \mathrm{D}_{6}$. After a day, NMR analysis revealed again the presence of $\mathrm{BCy}_{3}$ as well as tricyclohexyldiborane. We also noticed the formation of two new metal complexes according to ${ }^{31} \mathrm{P}\left\{{ }^{1} \mathrm{H}\right\}$ NMR with singlets at $\delta 45.2$ and 41.7 ppm, 2 remaining the major product of the mixture. Hoping to reach higher conversion, we increased the amount of $\mathrm{HBCy}_{2}$. ${ }^{31} \mathrm{P} \mathrm{NMR}$ analysis of the reaction mixture run with four equivalents thereof during 2 hours at $60^{\circ} \mathrm{C}$ revealed conversion to compound 7 (Scheme 2 , bottom). The ${ }^{1} \mathrm{H}$ NMR spectrum of the crude reaction mixture showed a hydride quintet coupling to four magnetically equivalent phosphorus nuclei $\left(\delta-3.38\right.$, quintet, ${ }^{2} J_{\mathrm{HP}}=30 \mathrm{~Hz}$ ). Diagnostic signals for a four-coordinated boron species carrying 2 hydrogens were observed in the ${ }^{1} \mathrm{H}$ and ${ }^{11} \mathrm{~B}$ NMR spectra $\left({ }^{1} \mathrm{H}\right.$ : $\delta 3.29$, broad singlet; ${ }^{1} \mathrm{H}\left\{{ }^{11} \mathrm{~B}\right\}$ : $\delta 3.29$, singlet; ${ }^{11} \mathrm{~B}: \delta-30.0$, triplet, $J_{\mathrm{BH}}=91 \mathrm{~Hz}$ ). Layering a concentrated toluene solution with pentane afforded crystalline material (76\% yield) suitable for an X-ray diffraction study. This allowed us to confirm that the targeted formal 1,3-B-H bond addition had been achieved, with $\mathrm{H}_{2} \mathrm{BCy}$ being the actual borylating agent (Fig. 1), thus explaining the need for an excess of $\mathrm{HBCy}_{2}$ to reach full conversion of $\mathbf{2}$.

In the molecular structure, a second, tetracoordinated boron moiety is found. Its presence is explained by the capture of another equivalent of $\mathrm{H}_{2} \mathrm{BCy}$, forming a Lewis pair with the distal, Lewis basic nitrogen of the boryldiazenido moiety [N2B2 1.618(6) Å]. The latter could not be observed in the ${ }^{11} \mathrm{~B} N M R$ spectrum and is characterised by a $\mathrm{B}-\mathrm{N}$ linkage having double bond character [N2-B1 1.405(6) Å). ${ }^{10}$ The distal $\mathrm{N}$ atom adopts a trigonal planar geometry $\left(\sum\right.$ angles $\left.=360^{\circ}\right)$, yet the wide $\mathrm{B}-\mathrm{N}-\mathrm{B}$ angle $\left(126^{\circ}\right)$, presumably originating from steric repulsions between the boron substituents, deviates it from ideality. The $\mathrm{N}-\mathrm{N}$ bond length [1.346(3) $\AA$ ] lies halfway between the ones of double (ca. $1.25 \AA$ ) and single (ca. $1.45 \AA$ ) $\mathrm{N}-\mathrm{N}$ bonds. This noticeable elongation $\left(d_{N-N} 1.1233(17) \AA\right.$ in 2 ) results from the formal two-electron reduction of the $\mathrm{N}_{2}$ ligand upon functionalisation, as well as the effect of $\mathrm{H}_{2} \mathrm{BCy}$ complexation pulling electron density from the metal into antibonding orbitals of the boryldiazenido ligand. ${ }^{11}$ The $\mathrm{W}-\mathrm{N}$ bond is 1.789 (2) $\AA$ long, indicative of double bond character, ${ }^{12}$ and the $\mathrm{W}$ centre lies in a distorted octahedron (all P-W-N angles $>90^{\circ}$ and up to $106^{\circ}$ ). Likewise, the W-N-N unit deviates from linearity [W1-N1-N2 $170^{\circ}$ ]. Those deviations from ideal geometries are, again, probably of steric origin. Overall, these structural features compare well with those of the previously reported compound 6 (Scheme 1). ${ }^{5 b}$

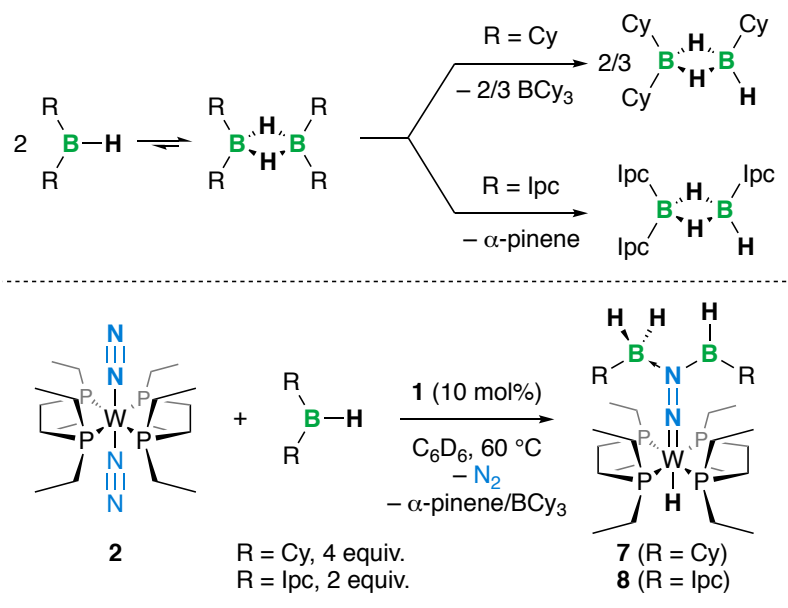

Scheme 2 Generation of monoalkylboranes from $\mathrm{HBR}_{2}$ (top) and reactions of trans[W( $\left.\mathrm{N}_{2}\right)_{2}$ (depe $\left.)_{2}\right](2)$ in the presence of dicyclohexyl- or diisopinocampheylborane catalysed by $\mathbf{1}$ (bottom).

Comparatively to $\mathrm{HBCy}_{2}$, diisopinocampheylborane ( $\left.\mathrm{HBIpc}_{2}\right)$ did not react with 2 even under forcing conditions. At room temperature and in $\mathrm{C}_{6} \mathrm{D}_{6}, \mathrm{HBIpC}_{2}$ also underwent a substituent rearrangement (Scheme 2, top). Indeed, its dimer evolves into triisopinocampheyldiborane and $\alpha$-pinene (see Fig. S6).9a Having established from the above-discussed reaction involving $\mathrm{HBCy}_{2}$ that dihydroboranes seem to add more easily to the W$\mathrm{N}_{2}$ unit than monohydroboranes, we adjusted the number of equivalents of $\mathrm{HBIpc}_{2}$ in order to generate the right amount of $\mathrm{H}_{2} \mathrm{Blpc}$ in the reaction mixture, and added a catalytic amount (10 mol\%) of 1 . With two equivalents of $\mathrm{HBlpc}_{2}$, full and selective conversion of $\mathbf{2}$ to compound $\mathbf{8}$ was reached after 15 $\min$ at $60{ }^{\circ} \mathrm{C}$ (Scheme 2, bottom). Although the newly formed compound $\mathbf{8}$ could not be crystallised, its NMR characterisations are very similar to compound 7: the ${ }^{1} \mathrm{H}$ NMR spectrum showed a hydride signal coupling to the four phosphorus $(\delta-3.33$, quintet, ${ }^{2} J_{\mathrm{HP}}=30.6 \mathrm{~Hz}$ ), and the ${ }^{11} \mathrm{~B} \mathrm{NMR}$ featured a triplet at 30.0 ppm, leaving little doubt on the identity of 8 .

\section{Reactions with 9-Borabicyclo[3.3.1]nonane (9-BBN)}

The reactivity of trans-[W( $\left.\left.\mathrm{N}_{2}\right)_{2}(\text { depe })_{2}\right] 2$ with one equivalent of 9-borabicyclo[3.3.1]nonane (9-BBN) at room temperature in $\mathrm{C}_{6} \mathrm{D}_{6}$ was also examined. Likewise, no reaction occurred even under forcing conditions $\left(2 \mathrm{~d}, 80^{\circ} \mathrm{C}\right)$. Hence, we added $10 \mathrm{~mol} \%$ of hydroborane 1 to an equimolar solution of $\mathbf{2}$ and 9-BBN. ${ }^{31} \mathrm{P}\left\{{ }^{1} \mathrm{H}\right\} N M R$ monitoring of the reaction after few days at $60^{\circ} \mathrm{C}$ revealed that two new products $\mathbf{9}$ and $\mathbf{1 0}$ started to form $(\delta 45.0$ and $40.7 \mathrm{ppm}$, respectively), both showing a corresponding hydride quintet in ${ }^{1} \mathrm{H}$ NMR $(\delta-3.33$ and $-4.10 \mathrm{ppm}$, respectively). Upon prolonged heating, compound $\mathbf{9}$ formed predominantly, reaching ca. $70 \%$ of the mixture according to ${ }^{31} \mathrm{P}$ NMR integration after 14 days at $70^{\circ} \mathrm{C}$ and on the basis of NMR spectroscopy, was assigned to the product of $1,3-\mathrm{B}-\mathrm{H}$ bond addition (Scheme 3). The other tungsten-containing components of the reaction mixture were $\mathbf{2}$ and unidentified minor impurities (see Fig. S12), while several unidentified boron species seemed to be present (Fig. S13). The slow rate of this B$\mathrm{H}$ bond addition incited us to perform the stoichiometric 
reaction between complex 2, 1 and 9-BBN. Analysis of the reaction mixture by ${ }^{31} \mathrm{P}$ NMR showed full and selective conversion to compound $\mathbf{1 0}$ (Scheme 3 ) after $4 \mathrm{~h}$ at $60^{\circ} \mathrm{C}$. Traces of $\mathbf{1 0}$ were also observed in the ${ }^{31} \mathrm{P}$ and ${ }^{19} \mathrm{~F}$ NMR spectra acquired at the end of the catalytic reaction (see Fig. S14). Analysis of the ${ }^{19} \mathrm{~F}$ and ${ }^{11} \mathrm{~B}$ NMR spectra of 10 suggested, in accordance with previous results, ${ }^{5 b}$ that it is formed by Lewis acid-base interaction of $\mathbf{1}$ with the boryldiazenido moiety of $\mathbf{9}$. The reaction of $\mathbf{9}$ with $\mathbf{1}$ to give $\mathbf{1 0}$ brought convincing evidences supporting the latter assumption, as well as the identity of $\mathbf{9}$, for which we could not ascertain the structure with X-ray diffraction.

An X-ray diffraction study on single crystals allowed us to confirm the proposed structure for $\mathbf{1 0}$ (Fig. 1), the covalent vs. dative bonding between the boron atoms and the terminal $\mathrm{N}$ being confirmed by comparison of $\mathrm{B}-\mathrm{N}$ bond lengths [N2-B1, 1.405(6) Å vs. N2-B2, 1.617(6) ̊̊]. The structure of 10 resembles the one of $\mathbf{7}$ with a tungsten centre in a distorted octahedron, and the $\mathrm{W}-\mathrm{N}-\mathrm{N}$ unit deviating from linearity (W1-N1-N2, 175 ${ }^{\circ}$. While $\mathrm{W}-\mathrm{N}$ bond lengths are similar in $\mathbf{7}$ and 10 , the $\mathrm{N}-\mathrm{N}$ bond in $\mathbf{1 0}$ is slightly longer $(+0.03 \AA)$, probably as a result of the higher electrophilicity of Piers' borane than $\mathrm{H}_{2} \mathrm{BCy}$.

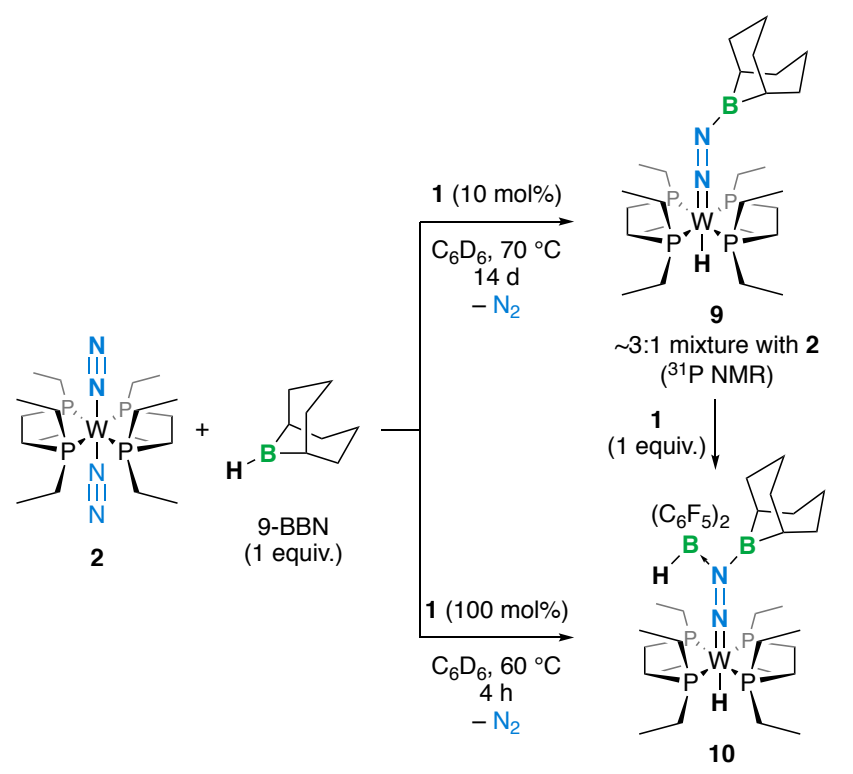

Scheme 3 Reactions of trans-[W( $\left.\left(\mathrm{N}_{2}\right)_{2}(\text { depe })_{2}\right]$ (2) with 9-BBN and catalytic or stoichiometric amounts of $\mathrm{HB}\left(\mathrm{C}_{6} \mathrm{~F}_{5}\right)_{2}(\mathbf{1})$.

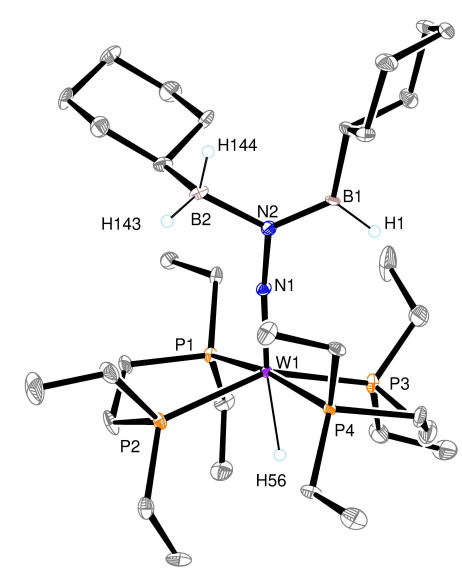

7

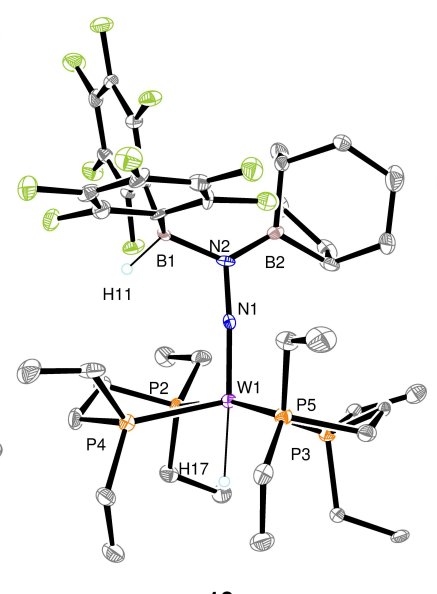

10

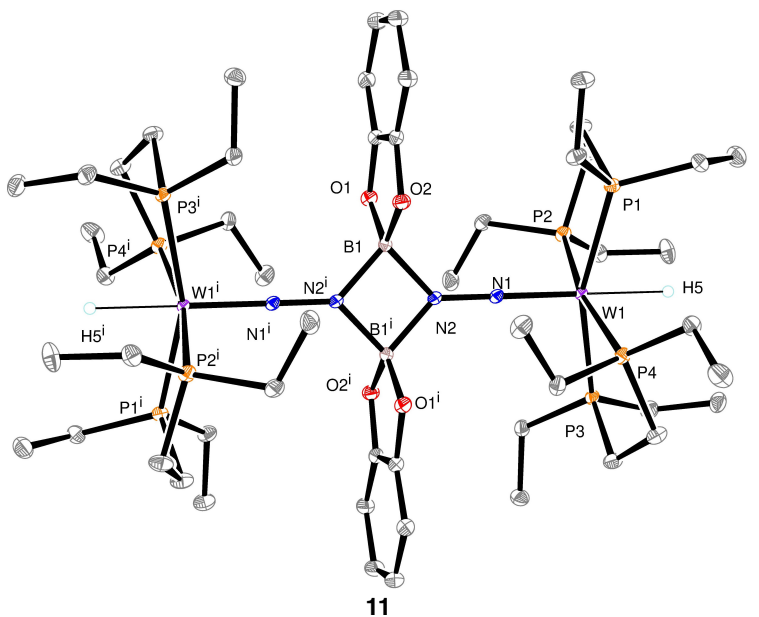

Fig. 1 Solid-state molecular structures of compounds 7,10 and 11. Ellipsoids drawn at the 50\% level of probability. All hydrogens have been omitted for clarity except those bound to B or W. Selected distances $(\AA ̊)$ and angles $\left({ }^{\circ}\right)$ for 7: W1-N1, 1.789(2); N1-N2, 1.346(3); N2-B1, 1.405(6); N2-B2, 1.618(6); W1-H56, 1.77(6); W1-N1-N2 170.3(3); B1-N2-B2 126.4(3). 10: W1-N1, 1.783(6); N1-N2, 1.383(9); N2-B1, 1.56(1); N2-B2, 1.41(1); W1-H17, 1.82; W1-N1-N2, 175.2(5); B1-N2-B2, 129.3(7). 11: W1-N1, 1.807(3); N1-N2, 1.295(4); N2-B1, 1.545(6); N2-B1i, 1.536(6); W1-H5, 1.87(5); W1-N1-N2, 178.6(3); B1-N2-B1, 94.1(3); N2-B1-N2, 85.9(3).

\section{Reaction with catecholborane (Hbcat)}

Next, we checked the reactivity of trans- $\left[\mathrm{W}\left(\mathrm{N}_{2}\right)_{2}(\text { depe })_{2}\right] 2$ with one equivalent of catecholborane (HBcat) at room temperature in $\mathrm{C}_{6} \mathrm{D}_{6}$. Quite contrastingly, NMR analysis revealed that a reaction occurred in a selective manner. Indeed, we observed a new diamagnetic compound $\mathbf{1 1}$ having a singlet resonance at $\delta$ $43.8 \mathrm{ppm}$ in ${ }^{31} \mathrm{P}\left\{{ }^{1} \mathrm{H}\right\} \mathrm{NMR}$ with a corresponding hydride quintet at $-3.6 \mathrm{ppm}$ in ${ }^{1} \mathrm{H}$ NMR after few minutes at room temperature. Almost full conversion was obtained after 3 days at $60{ }^{\circ} \mathrm{C}(>90$ $\%$ according to ${ }^{31} \mathrm{P}$ NMR). Compared to the previous examples, Piers' borane $\mathbf{1}$ was not necessary to perform the targeted formal 1,3-B-H bond addition.

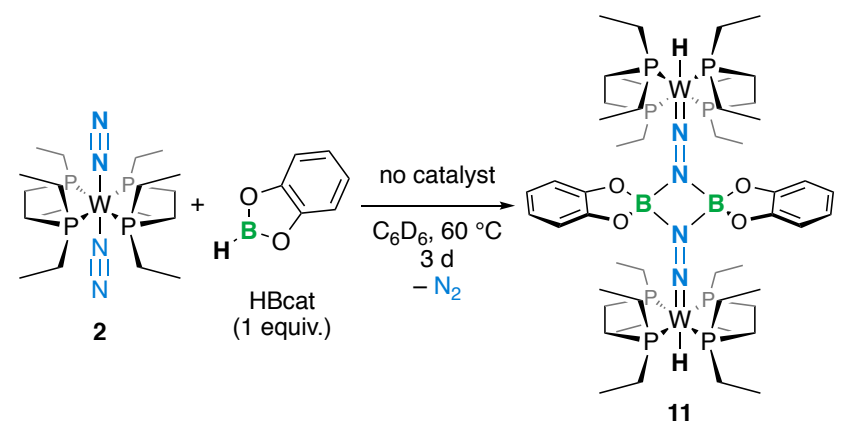

Scheme 4 Reaction of trans-[W( $\left.\left(\mathrm{N}_{2}\right)_{2}(\text { depe })_{2}\right] 1$ with catecholborane (HBcat).

Layering the reaction mixture with pentane allowed us to grow single crystals of $\mathbf{1 1}$ (33\% yield) suitable for X-ray 
diffraction analysis, that revealed a dimeric solid-state structure of $D_{2 \mathrm{~h}}$ symmetry for $\mathbf{7}$ (Fig. 1): two boryl groups are bridging two $\mathrm{W}-\mathrm{N}_{2}$ units in an almost square BNBN arrangement ( $\mathrm{N}-\mathrm{B}$ bond lengths ca. $1.54 \AA$ A $\mathrm{B}-\mathrm{N}-\mathrm{B}$ angles $94^{\circ}, \mathrm{N}-\mathrm{B}-\mathrm{N}$ angles $86^{\circ}$ ). Compared to the structures of $\mathbf{3}$ and $\mathbf{6}$, the octahedron formed by the $\mathrm{W}$ ligands is less distorted, and the $\mathrm{W}-\mathrm{N}-\mathrm{N}$ arrangement is linear $\left(\mathrm{W} 1-\mathrm{N} 1-\mathrm{N} 2,179^{\circ}\right)$. The $\mathrm{N}-\mathrm{N}$ bond is also shorter [1.295(4) Å]. Similar dimeric structures have been obtained from the reactions of group 13 chlorides with end-on dinitrogen complexes. ${ }^{13}$ The dimeric nature of $\mathbf{1 1}$ in the solid, which contrasts with the one of $\mathbf{7}$ or $\mathbf{9}$ (as suggested by diffusionordered NMR spectroscopy, see Fig. S15), is likely to result from the diminished steric hindrance of the flat Bcat group.

\section{Discussion}

The above-described experiments have confirmed the possibility to use Piers' borane as a catalyst for the borylation of $\mathrm{N}_{2}$ bound to a group 6 metal centre by $1,3-\mathrm{B}-\mathrm{H}$ bond addition when using dialkylhydroboranes $\left(\mathrm{HBCy}_{2}, \mathrm{HBIpc}_{2}\right.$ and 9-BBN). Within this family of compounds, two different behaviours have been observed depending on the propensity of the dialkylhydroborane to undergo retro-hydroboration under the reaction conditions to give a monoalkylborane. The latter is the active borylating agent, and in the case of $\mathrm{HBCY}_{2}$ and $\mathrm{HBIPC}_{2}$, only the products of 1,3-B-H bond addition of $\mathrm{H}_{2} \mathrm{BCy}$ and $\mathrm{H}_{2} \mathrm{BI}$ pc over the $\mathrm{W}-\mathrm{N}-\mathrm{N}$ unit were observed. The reason is most probably of kinetic origin, since monoalkylboranes are less sterically hindered than their disubstituted parents, making the interaction with the $\mathrm{N}_{2}$ complex as well as the $\mathrm{B}-\mathrm{H}$ bond activation by 1 easier. 9-BBN, which does not undergo retrohydroboration, reacts much slower and also needs catalytic amounts of 1 . Interestingly, when the reaction of 9-BBN with the dinitrogen complex is conducted in the presence of an equimolar amount of $\mathbf{1}$, the $\mathrm{B}-\mathrm{H}$ bond addition proceeds very rapidly and selectively. Indeed, the $1,3-\mathrm{B}-\mathrm{H}$ bond addition product of Piers' borane ${ }^{5 b}$ (3, Scheme 1$)$ is not observed. The following experiment allowed us to shed light on this fact: when product 3 was treated with an equimolar amount of 9-BBN at RT, 10 was obtained quantitatively in a few hours (Scheme 5). This result suggests that in the catalytic $1,3-\mathrm{B}-\mathrm{H}$ bond addition mechanism with $\mathrm{H}_{2} \mathrm{BCy}, \mathrm{H}_{2} \mathrm{BIpc}$ or 9-BBN, addition of Piers' borane to give $\mathbf{3}$ may precede interaction of the alkylhydroborane with the $\mathrm{M}-\mathrm{N} \equiv \mathrm{N}$ unit. After complexation of the latter to the thus-formed $\mathrm{C}_{6} \mathrm{~F}_{5}$-substituted boryldiazenido moiety in 3, boron-to-boron hydride transfer then affords a Piers' borane-complexed 1,3-B-H bond addition compound such as $\mathbf{1 0}$. Dissociation of $\mathbf{1}$ followed by reaction with dinitrogen complex $\mathbf{2}$ would then close the catalytic sequence. However, further experimental work cast doubts on this conjecture, at least in the case of 9-BBN. Attempts to dissociate $\mathbf{1}$ in compound $\mathbf{1 0}$ in the presence of various Lewis bases such as $\mathrm{PMe}_{3}$, pyridine, tetramethylethylenediamine (TMEDA) or $\mathbf{2}$ at elevated temperatures for several hours proved unsuccessful (Scheme 5, top). ${ }^{14}$ We have checked the integrity of Piers' borane (1) in the presence of a 10-fold excess of 9-BBN: at RT, a new species forms in $C_{6} D_{6}$ within few hours, which we believe is the mixed diborane $\mathbf{1 2}$ (Scheme 5, bottom). Upon heating to a temperature relevant to the above-described experiments, the putative dimer seems to get involved in an equilibrated substituent rearrangement process with two other compounds, one being $9-\mathrm{C}_{6} \mathrm{~F}_{5}-\mathrm{BBN}^{15}$ (13) while the second one is presumably a mixed diborane composed of 9-BBN and in-situ-formed $\mathrm{H}_{2} \mathrm{BC}_{6} \mathrm{~F}_{5}$ (see Fig. S22-23 and Scheme 5). The ${ }^{19} \mathrm{~F}$ NMR spectrum recorded at the end of the reaction affording 9 does not feature the spectral signature of $\mathbf{1}$, but unambiguously shows the presence of $\mathbf{1 0}$ along with another unidentified compound (see Fig. S13-14). These data suggests that 1 is a precatalyst in the reaction involving 9-BBN, but the presence of $\mathbf{1 0}$ at the end of the reaction also implies this species might be a catalyst resting state.

HBcat stands out against the 3 other boranes examined. This boron reagent is known to be a much milder hydroboration reagent than $\mathrm{HBCy}_{2}$ or $\mathrm{HBIpc}_{2}$, due to its quenched Lewis acidity. ${ }^{16}$ As such, $\mathrm{HBcat}$ is also a weak hydride donor compared to 9-BBN on the basis of calculated hydride donor abilities $\left[\Delta G_{\mathrm{H}}\right.$ $(298 \mathrm{~K})=159.2$ vs. $99.0 \mathrm{kcal} / \mathrm{mol}$, respectively], but this trend reverses upon Lewis base [for example, NHC-HBcat, $\Delta G_{\mathrm{H}-}(298 \mathrm{~K})$ $=44.8 \mathrm{kcal} / \mathrm{mol}$ and NHC-9-BBN, $\Delta G_{\mathrm{H}-}(298 \mathrm{~K})=47.0$ with NHC= 1,3-di(isopropyl)imidazole-2-ylidene] or hydride coordination $\left\{\left[\mathrm{H}_{2} \mathrm{BCat}\right]^{-}, \Delta G_{\mathrm{H}-}(298 \mathrm{~K})=26.3 \mathrm{kcal} / \mathrm{mol}\right.$ and $\left[9-\mathrm{H}_{2} \mathrm{BBN}\right]^{-}, \Delta G_{\mathrm{H}-}$ $(298 \mathrm{~K})=32.8\} .{ }^{17}$ Although the flatness of HBcat and its monomeric nature in non-coordinating solvents also offers a kinetic advantage, we believe the peculiarity of HBcat reactivity lies in its electronic properties. We propose a similar mechanism for 1,3-B-H bond addition of HBcat than with Piers' borane (Scheme 1): Lewis acid-base adduct formation of HBcat with 2 increases the polarisation of the $\mathrm{B}-\mathrm{H}$ bond to an extent that a second equivalent of $\mathrm{HBcat}$ is now able to abstract the hydride, generating the $\left[\mathrm{H}_{2} \mathrm{Bcat}\right]^{-}$anion. The latter is a competent hydride donor (vide supra), especially when compared to $\left[\mathrm{H}_{2} \mathrm{~B}\left(\mathrm{C}_{6} \mathrm{~F}_{5}\right)_{2}\right]^{-}\left[\Delta G_{\mathrm{H}-}(298 \mathrm{~K})=61.5 \mathrm{kcal} / \mathrm{mol}\right]$, which also bears a steric penalty due to its $\mathrm{C}_{6} \mathrm{~F}_{5}$ substituents. This may explain why in the reactions with $\mathrm{HBcat}$ we were not able to detect species resembling $\mathbf{5}$ (Scheme 1 ), the $\mathrm{W}-\mathrm{H}$ bond formation event being probably too fast under the experimental conditions. In the case of Piers' borane, we surmise that an important factor for $\mathrm{W}-\mathrm{H}$ bond formation ( $5 \rightarrow 6$, Scheme 1 ) is the nature of the trans ligand, $\mathrm{NNB}\left(\mathrm{C}_{6} \mathrm{~F}_{5}\right)_{2}$, which electron-withdrawing properties might counter-balance the weak hydride donor ability of $\left[\mathrm{H}_{2} \mathrm{~B}\left(\mathrm{C}_{6} \mathrm{~F}_{5}\right)_{2}\right]^{-} .{ }^{18}$ 

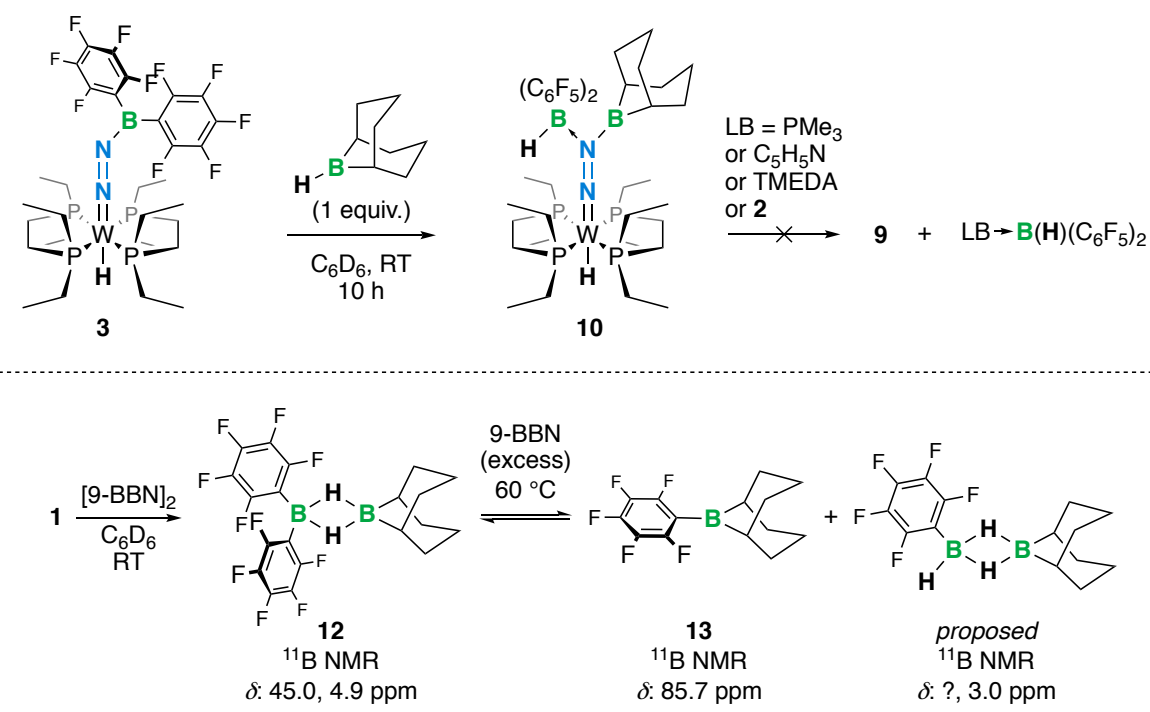

Scheme $\mathbf{5}$ Reaction of $\mathbf{3}$ with 9-BBN and attempts to dissociate $\mathbf{1}$ from $\mathbf{1 0}$ with various Lewis bases (top) and reaction of $\mathbf{1}$ with 9-BBN in the absence of a dinitrogen complex (bottom)

\section{Conclusions}

In the present article, we expand the scope of $1,3-\mathrm{B}-\mathrm{H}$ bond addition over a W- $\mathrm{N}_{2}$ unit. This mild method for $\mathrm{N}_{2}$ borylation, which complements $1,3-\mathrm{B}-\mathrm{X}$ bond addition, ${ }^{7}$ can be attractive for who seeks to synthesise nitrogen-boron compounds directly from dinitrogen. Having this goal in mind, we have examined the reactivity of 4 different boranes. Only HBcat reacts spontaneously with the dinitrogen complex $\mathbf{2}$, affording the 1,3$\mathrm{B}-\mathrm{H}$ bond addition product 11 . Hydroboranes $\mathrm{HBCy}_{2}, \mathrm{HBIpC}_{2}$ and 9-BBN required catalytic amounts of Piers' borane (1) to react with 2. In the case of $\mathrm{HBCy}_{2}$ and $\mathrm{HBIPC}_{2}$, monoalkylboranes $\mathrm{H}_{2} \mathrm{BCy}$ and $\mathrm{H}_{2} \mathrm{Blpc}$ formed in-situ are the actual borylating agents. None of the boranes examined have allowed to build more than one covalent $\mathrm{N}-\mathrm{B}$ bond. According to experimental observations, we believe the mechanism of these catalytic reactions starts with $1,3-\mathrm{B}-\mathrm{H}$ bond addition of $\mathbf{1}$ to give $\mathbf{3}$, followed by complexation of the alkylhydroborane to the terminal $\mathrm{N}$ of the resulting $\mathrm{W}$-ligated boryldiazenido ligand and a boron-to-boron hydride transfer ensues. While it is reasonable to think that dissociation of $\mathbf{1}$ should close the catalytic cycle, such elementary step could not be validated in the case of 9BBN because $\mathbf{1}$ is likely to be a precatalyst in this specific reaction. This urges us to explore in detail the reactivity of $\mathrm{H}_{2} \mathrm{BC}_{6} \mathrm{~F}_{5}$ but also $\mathrm{L} \bullet \mathrm{BH}_{3}\left(\mathrm{~L}=\mathrm{THF}, \mathrm{SMe} \mathrm{e}_{2}\right.$, etc...) or diborane $\left(\mathrm{B}_{2} \mathrm{H}_{6}\right)$ with zero-valent group 6 dinitrogen complexes. We will share the results of this future work in due time.

\section{Experimental Section}

\section{General considerations}

All reactions were performed in flame- or oven-dried glassware with rigorous exclusion of air and moisture, using a nitrogen filled Jacomex glove box $\left(\mathrm{O}_{2}<1 \mathrm{ppm}, \mathrm{H}_{2} \mathrm{O}<1 \mathrm{ppm}\right)$. Solvent used were pre-dried (toluene and $n$-pentane by passing through a Puresolv MD 7 solvent purification machine; $n$-hexane and hexamethyldisiloxane (HMDSO) by distillation over $\mathrm{CaH}_{2}$ ), degassed by freeze-pump-thaw cycles, dried over molecular sieves and stored in the glove box. $\mathrm{C}_{6} \mathrm{D}_{6}$ (purchased from Eurisotop) was degassed by freeze-pump-thaw cycles, dried over molecular sieves and stored in the glove box. $\mathrm{HB}\left(\mathrm{C}_{6} \mathrm{~F}_{5}\right)_{2}$ (1), ${ }^{6 a} \mathrm{HBCy}_{2}{ }^{19}$ and $\mathrm{HBIPC}_{2}{ }^{20}$ were synthesized according to reported procedures and stored in the glove box. 9-BBN and $\mathrm{HBC}$ at were purchased from Sigma-Aldrich and used as received in the glove box. ${ }^{1} \mathrm{H},{ }^{11} \mathrm{~B},{ }^{19} \mathrm{~F}$ and ${ }^{31} \mathrm{P}$ NMR spectra were recorded in $\mathrm{C}_{6} \mathrm{D}_{6}$ or toluene- $d_{8}$ using NMR tubes equipped with J. Young valves on a Bruker Avance III 400 spectrometer. Chemical shifts are in parts per million (ppm) downfield from tetramethylsilane and are referenced to the residual solvent resonance as the internal standard $\left(\mathrm{C}_{6} \mathrm{HD}_{5}: \delta\right.$ reported $=7.16 \mathrm{ppm} ; \mathrm{C}_{7} \mathrm{HD}_{7}: \delta$ reported $=2.08 \mathrm{ppm}$ for $\left.{ }^{1} \mathrm{H} N M R\right) .{ }^{11} \mathrm{~B},{ }^{19} \mathrm{~F},{ }^{29} \mathrm{Si}$ and ${ }^{31} \mathrm{P} N M R$ spectra were calibrated according to the IUPAC recommendation using a unified chemical shift scale based on the proton resonance of tetramethylsilane as primary reference. ${ }^{21}$ Data are reported as follows: chemical shift, multiplicity $(\mathrm{br}=$ broad, $\mathrm{s}=$ singlet, $\mathrm{d}=$ doublet, $\mathrm{t}=$ triplet, $\mathrm{q}=$ quartet, quint $=$ quintet, $\mathrm{m}=$ multiplet, $\mathrm{m}_{\mathrm{c}}=$ centrosymmetric multiplet), coupling constant $(\mathrm{Hz})$, and integration. Infrared (IR) spectra were recorded in the glove box on an Agilent Cary 630 FT-IR spectrophotometer equipped with ATR or transmission modules and are reported in wavenumbers $\left(\mathrm{cm}^{-1}\right)$. Elemental analyses were performed on samples sealed in tin capsules under $\mathrm{N}_{2}$ by the Analytical Service of the Laboratoire de Chimie de Coordination; results are the average of two independent measurements.

\section{Reaction of 2 with $\mathrm{HBC}_{2}$ catalysed by 1}

In a glovebox, trans-[W( $\left.\left(\mathrm{N}_{2}\right)_{2}(\text { depe })_{2}\right](2,52 \mathrm{mg}, 80 \mu \mathrm{mol}, 1$ equiv.), $\mathrm{HBCy}_{2}$ (57 mg, $32 \mu \mathrm{mol}, 4$ equiv.) and $\mathrm{HB}\left(\mathrm{C}_{6} \mathrm{~F}_{5}\right)_{2}(1,3 \mathrm{mg}$, $8 \mu \mathrm{mol}, 0.1$ equiv.) were weighed in a $4-\mathrm{mL}$ vial. After addition of $\mathrm{C}_{6} \mathrm{D}_{6}(0.6 \mathrm{~mL})$, the orange-red solution was heated for 2 hours at $60^{\circ} \mathrm{C}$. The resulting orange solution was concentrated to $c a$. $0.3 \mathrm{~mL}$ under reduce pressure and layered with pentane before 
storage at $-40{ }^{\circ} \mathrm{C}$. After a week, orange crystals of 7 were recovered by decantation and dried under vacuum $(50 \mathrm{mg}, 61$ $\mu \mathrm{mol}, 76 \%$ yield). Single crystals suitable for an $\mathrm{X}$-ray diffraction study were obtained from the same crop.

7: ${ }^{1} \mathrm{H}$ NMR (400 MHz, $\left.\mathrm{C}_{6} \mathrm{D}_{6}\right) \delta: 3.29(\mathrm{br} \mathrm{s}, 2 \mathrm{H}), 2.21-2.02\left(\mathrm{~m}_{\mathrm{c}}\right.$, $8 \mathrm{H}), 2.06(\mathrm{t}, J=11.6 \mathrm{~Hz}, 8 \mathrm{H}), 1.94(\mathrm{~s}, 2 \mathrm{H}), 1.82-1.63(\mathrm{~m}, 5 \mathrm{H})$, $1.63-1.38(\mathrm{~m}, 14 \mathrm{H}), 1.39-1.18(\mathrm{~m}, 10 \mathrm{H}), 1.14$ (quint, $J=7.6 \mathrm{~Hz}$, $12 \mathrm{H}$ ), $0.73\left(\mathrm{p}, J=7.4 \mathrm{~Hz}, 12 \mathrm{H}\right.$ ), -3.38 (quint, $J_{\mathrm{HW}}=15.8 \mathrm{~Hz}, J_{\mathrm{HP}}=$ $30.4 \mathrm{~Hz}, 1 \mathrm{H}) .{ }^{31} \mathrm{P}\left\{{ }^{1} \mathrm{H}\right\}$ NMR $\left(162 \mathrm{MHz}, \mathrm{C}_{6} \mathrm{D}_{6}\right) \delta: 41.7\left(J_{\mathrm{PW}}=282\right.$ $\mathrm{Hz}) .{ }^{11} \mathrm{~B}$ NMR $\left(128 \mathrm{MHz}, \mathrm{C}_{6} \mathrm{D}_{6}\right) \delta:-30.0\left(\mathrm{t}, \mathrm{J}_{\mathrm{BH}}=91.0 \mathrm{~Hz}\right)$.

IR (ATR) v/cm ${ }^{-1}=2958,2900,2783,1603,1503,1456,1362$, $1335,1274,1188,1163,1124,1095,1081,1029,982,867,802$, 755, 732, 710, 693, 686, 662.

Elem. Anal. calcd. for $\mathrm{C}_{32} \mathrm{H}_{74} \mathrm{~B}_{2} \mathrm{~N}_{2} \mathrm{P}_{4} \mathrm{~W}: \mathrm{C}, 47.08 ; \mathrm{H}, 9.14 ; \mathrm{N}$, 3.43. Found: $C, 47.10 ; \mathrm{H}, 8.90 ; \mathrm{N}, 3.26$.

\section{Reaction of 2 with $\mathrm{HBIpc}_{2}$ catalysed by 1}

In a glovebox, trans-[W( $\left.\left(\mathrm{N}_{2}\right)_{2}(\text { depe })_{2}\right](2,13 \mathrm{mg}, 20 \mu \mathrm{mol}, 1$ equiv.), $\mathrm{HBIpc}_{2}\left(12 \mathrm{mg}, 40 \mu \mathrm{mol}, 2\right.$ equiv.) and $\mathrm{HB}\left(\mathrm{C}_{6} \mathrm{~F}_{5}\right)_{2}(\mathbf{1}, 0.7$ $\mathrm{mg}, 2.0 \mu \mathrm{mol}, 0.1$ equiv.) were weighed in a $4-\mathrm{mL}$ vial. After addition of $C_{6} D_{6}(0.6 \mathrm{~mL})$, the orange-red solution was heated at $60^{\circ} \mathrm{C}$ for 15 minutes, time after which full conversion of $\mathbf{2}$ into 8 was ascertained by NMR analysis. After evaporation to dryness in the glovebox, the oily residue was triturated in pentane. The supernatant was discarded, and the oily residue was dried under vacuum. Compound $\mathbf{8}$ could not be isolated otherwise than as a $\mathrm{C}_{6} \mathrm{D}_{6}$-containing clathrate.

8: ${ }^{1} \mathrm{H}$ NMR (400 MHz, $\left.\mathrm{C}_{6} \mathrm{D}_{6}\right) \delta: 3.38(\mathrm{br} \mathrm{s}, 3 \mathrm{H}), 2.59-2.50(\mathrm{~m}$, $2 \mathrm{H}), 2.43-2.34(\mathrm{~m}, 4 \mathrm{H}), 2.27-2.13(\mathrm{~m}, 12 \mathrm{H}), 2.06-1.97(\mathrm{~m}, 3 \mathrm{H})$, $1.82(\mathrm{~m}, 2 \mathrm{H}), 1.74-1.65(\mathrm{~m}, 3 \mathrm{H}), 1.48(\mathrm{~d}, J=7.2 \mathrm{~Hz}, 8 \mathrm{H}), 1.45(\mathrm{~s}$, $6 \mathrm{H}), 1.37(\mathrm{~s}, 6 \mathrm{H}), 1.20-1.10(\mathrm{~m}, 16 \mathrm{H}), 0.80-0.68(\mathrm{~m}, 2 \mathrm{OH}),-3.33$ (quint, $\left.J_{\mathrm{HW}}=13.4 \mathrm{~Hz}, J_{\mathrm{HP}}=30.7 \mathrm{~Hz}, 1 \mathrm{H}\right) .{ }^{31} \mathrm{P}\left\{{ }^{1} \mathrm{H}\right\} \mathrm{NMR}(162 \mathrm{MHz}$, $\left.\mathrm{C}_{6} \mathrm{D}_{6}\right) \delta: 41.2\left(\mathrm{~m}_{\mathrm{c}}, J_{\mathrm{WP}}=282 \mathrm{~Hz}\right.$, second order pattern). 31P NMR (162 $\left.\mathrm{MHz}, \mathrm{C}_{6} \mathrm{D}_{6}\right) \delta: 41.2$ ( $\mathrm{m}_{\mathrm{c}}$, second order pattern). ${ }^{11} \mathbf{B}$ NMR $\left(128 \mathrm{MHz}, \mathrm{C}_{6} \mathrm{D}_{6}\right) \delta:-3.32(\mathrm{br} \mathrm{s}),-30.0\left(\mathrm{t}, J_{\mathrm{BH}}=88.9 \mathrm{~Hz}\right)$.

IR (ATR) v/cm $\mathrm{cm}^{-1}=2962,2936,2878,2357,2081,1634,1501$, $1453,1416,1293,1104,1074,1027,961,869,806,751,735$, 683.

Elem. Anal. calcd. for $\mathrm{C}_{40} \mathrm{H}_{86} \mathrm{~B}_{2} \mathrm{~N}_{2} \mathrm{P} 4 \mathrm{~W} \cdot 0.55 \mathrm{C}_{6} \mathrm{D}_{6}$ : $\mathrm{C}, 53.58 ; \mathrm{H}$, 8.93; N, 2.89. Found: C, 54.09; H, 9.55; N, 2.56.

\section{Reaction of 2 with 9-BBN catalysed by 1}

In a glovebox, trans-[W( $\left(\mathrm{N}_{2}\right)_{2}$ (depe $\left.)_{2}\right](2,26 \mathrm{mg}, 40 \mu \mathrm{mol}, 1$ equiv.), 9-BBN (4.9 mg, $40 \mu \mathrm{mol}, 1$ equiv.) and $\mathrm{HB}\left(\mathrm{C}_{6} \mathrm{~F}_{5}\right)_{2}(\mathbf{1}, 1.4$ $\mathrm{mg}, 4.0 \mu \mathrm{mol}, 0.1$ equiv.) were weighed in a $4-\mathrm{mL}$ vial. After addition of $\mathrm{C}_{6} \mathrm{D}_{6}(0.5 \mathrm{~mL})$, the dark orange solution was heated at $70{ }^{\circ} \mathrm{C}$ for 14 days, time after which compound 9 become the main component of the reaction mixture (ca. $70 \%$ according to ${ }^{31} \mathrm{P}$ NMR) that still contained $\mathbf{2}$ and other unidentified boron species. Attempts to isolate $\mathbf{9}$ in an analytically pure form have failed.

9: ${ }^{1} \mathrm{H}$ NMR (400 MHz, $\left.\mathrm{C}_{6} \mathrm{D}_{6}\right) \delta: 2.08-1.99(\mathrm{~m}, 12 \mathrm{H}), 1.89-$ $1.85(\mathrm{~m}, 3 \mathrm{H}), 1.80-1.71(\mathrm{~m}, 6 \mathrm{H}), 1.68-1.62(\mathrm{~m}, 3 \mathrm{H}), 1.51(\mathrm{~s}, 2 \mathrm{H})$, $1.47-1.34(\mathrm{~m}, 12 \mathrm{H}), 1.17(\mathrm{dt}, \mathrm{J}=14.8,7.6 \mathrm{~Hz}, 12 \mathrm{H}), 0.87(\mathrm{dt}, \mathrm{J}=$ 13.6, 7.5 Hz, 12H), -3.33 (quint, $J_{\mathrm{HW}}=26.1 \mathrm{~Hz}, J_{\mathrm{HP}}=26.3 \mathrm{~Hz}, 1 \mathrm{H}$ ). ${ }^{31} \mathbf{P}\left\{{ }^{1} \mathrm{H}\right\}$ NMR $\left(162 \mathrm{MHz}, \mathrm{C}_{6} \mathrm{D}_{6}\right) \delta: 45.03\left(J_{\mathrm{WP}}=282 \mathrm{~Hz}\right) .{ }^{11} \mathbf{B} \mathbf{N M R}$ $\left(128 \mathrm{MHz}, \mathrm{C}_{6} \mathrm{D}_{6}\right) \delta: 45.9$.

\section{Reaction of 2 with 9-BBN and 1}

In a glovebox, trans-[W( $\left.\left(\mathrm{N}_{2}\right)_{2}(\text { depe })_{2}\right](2,20 \mathrm{mg}, 30 \mu \mathrm{mol}, 1$ equiv.), 9-BBN (3.8 mg, $30 \mu \mathrm{mol}, 1$ equiv.) and $\mathrm{HB}\left(\mathrm{C}_{6} \mathrm{~F}_{5}\right)_{2}(2,10$ $\mathrm{mg}, 30 \mu \mathrm{mol}, 1$ equiv.) were weighed in a $4-\mathrm{mL}$ vial. After addition of $\mathrm{C}_{6} \mathrm{D}_{6}(0.6 \mathrm{~mL})$, the dark orange solution was heated at $60^{\circ} \mathrm{C}$ for 4 hours. The resulting orange solution was concentrated under vacuum and pentane $(2 \mathrm{~mL})$ was added before storage at $-40{ }^{\circ} \mathrm{C}$. After one day, orange crystals of $\mathbf{1 0}$ were recovered by decantation and dried under vacuum $(23 \mathrm{mg}$, $21 \mu \mathrm{mol}, 70 \%$ yield). Single crystals suitable for $\mathrm{X}$-ray diffraction crystallography were obtained from the same crop.

10: ${ }^{1} \mathrm{H}$ NMR (400 MHz, $\left.\mathrm{C}_{6} \mathrm{D}_{6}\right) \delta: 3.98(\mathrm{~d}, J=107.1 \mathrm{~Hz}, 1 \mathrm{H})$, $2.15-1.98(\mathrm{~m}, 4 \mathrm{H}), 1.97-1.85(\mathrm{~m}, 4 \mathrm{H}), 1.85-1.77(\mathrm{~m}, 2 \mathrm{H})$, $1.72(\mathrm{q}, J=4.7,4.2 \mathrm{~Hz}, 4 \mathrm{H}), 1.65-1.44(\mathrm{~m}, 10 \mathrm{H}), 1.39-1.26(\mathrm{~m}$, $6 \mathrm{H}$ ), $1.22-1.07(\mathrm{~m}, 8 \mathrm{H}), 1.00$ (quint, $J=7.4 \mathrm{~Hz}, 12 \mathrm{H}$ ), 0.62 (quint, $J_{\mathrm{HW}}=9.8 \mathrm{~Hz}, J_{\mathrm{HP}}=7.4 \mathrm{~Hz}, 12 \mathrm{H}$ ), -4.10 (quint, $J_{\mathrm{HP}}=34.1 \mathrm{~Hz}, 1 \mathrm{H}$ ). ${ }^{31} \mathbf{P}\left\{{ }^{1} \mathrm{H}\right\}$ NMR $\left(162 \mathrm{MHz}, \mathrm{C}_{6} \mathrm{D}_{6}\right) \delta: 40.7\left(J_{\mathrm{PW}}=287 \mathrm{~Hz}\right) .{ }^{11} \mathbf{B}$ NMR (128 MHz, $\left.\mathrm{C}_{6} \mathrm{D}_{6}\right) \quad \delta:-10.9(\mathrm{~s})$, the boron shift of the tricoordinated boryl group could not be detected. ${ }^{19} \mathrm{~F}$ NMR (377 $\left.\mathrm{MHz}, \mathrm{C}_{6} \mathrm{D}_{6}\right) \delta:-132.7\left(\mathrm{dd}, \mathrm{J}_{F F}=25.5,9.3 \mathrm{~Hz}, 4 \mathrm{~F}_{\text {ortho }}\right),-162.5\left(\mathrm{t}, J_{F F}\right.$ $\left.=20.2 \mathrm{~Hz}, 2 \mathrm{~F}_{\text {para }}\right),-166.0--166.5\left(\mathrm{~m}, 4 \mathrm{~F}_{\text {meta }}\right)$.

IR $\left(\right.$ ATR) $\mathrm{v} / \mathrm{cm}^{-1}=2965,2937,2917,2881,2354,1639,1507$, $1452,1375,1332,1264,1228,1108,1091,1075,1039,1028$, 964, 936, 887, 869, 844, 803, 736, 712, 680, 662.

Elem. Anal. calcd. for $\mathrm{C}_{40} \mathrm{H}_{64} \mathrm{~B}_{2} \mathrm{~F}_{10} \mathrm{~N}_{2} \mathrm{P}_{4} \mathrm{~W}: \mathrm{C}, 43.98 ; \mathrm{H}, 5.91$; $N, 2.65$. Found: $C, 44.00 ; \mathrm{H}, 6.08 ; \mathrm{N}, 2.48$.

\section{Reaction of 2 with HBCat}

In a glovebox, trans-[W( $\left.\left(\mathrm{N}_{2}\right)_{2}(\text { depe })_{2}\right](2,52 \mathrm{mg}, 80 \mu \mathrm{mol}, 1$ equiv.) and HBCat ( $8.6 \mu \mathrm{L}, 80 \mu \mathrm{mol}, 1.0$ equiv.) were introduced in a 4- $\mathrm{mL}$ vial. After addition of $\mathrm{C}_{6} \mathrm{D}_{6}(0.6 \mathrm{~mL})$, the orange solution was heated at $60^{\circ} \mathrm{C}$ for 3 days. The resulting solution was then concentrated under vacuum before adding hexane ( 2 $\mathrm{mL}$ ). The resulting turbid solution was centrifuged, giving a yellow liquid that was stored at $-40{ }^{\circ} \mathrm{C}$. After a week, a mixture of crystals and powder of $\mathbf{1 1}$ were recovered by filtration and dried under vacuum (26.6 mg, $18 \mu \mathrm{mol}, 45 \%$ yield). Single crystals suitable for an X-ray diffraction study were obtained by layering pentane onto a saturated $\mathrm{C}_{6} \mathrm{D}_{6}$ solution of $\mathbf{1 1}$ before storage at $-40{ }^{\circ} \mathrm{C}(33 \%$ yield $)$.

11: ${ }^{1} \mathrm{H}$ NMR (400 MHz, $\left.\mathrm{C}_{6} \mathrm{D}_{6}\right) \delta: 6.90-6.86(\mathrm{~m}, 4 \mathrm{H}), 6.83-6.79$ ( $\mathrm{m}, 4 \mathrm{H}), 2.10-1.87(\mathrm{~m}, 16 \mathrm{H}), 1.70$ (ddd, $J=11.1,9.2,5.5 \mathrm{~Hz}, 8 \mathrm{H})$, $1.40-1.23(\mathrm{~m}, 24 \mathrm{H}), 1.15$ (quint, $J=7.4 \mathrm{~Hz}, 24 \mathrm{H}), 0.82-0.70(\mathrm{~m}$, $24 \mathrm{H}$ ), -3.60 (quint, $\left.J_{\mathrm{HW}}=18.1 \mathrm{~Hz}, J_{\mathrm{HP}}=29.2 \mathrm{~Hz}, 2 \mathrm{H}\right) .{ }^{31} \mathbf{P}\left\{{ }^{1} \mathrm{H}\right\} \mathbf{N M R}$ $\left(162 \mathrm{MHz}, \mathrm{C}_{6} \mathrm{D}_{6}\right) \delta: 43.8\left(\mathrm{~J}_{\mathrm{PW}}=286 \mathrm{~Hz}\right) .{ }^{11} \mathrm{~B} \mathrm{NMR}\left(128 \mathrm{MHz}, \mathrm{C}_{6} \mathrm{D}_{6}\right)$ $\delta: 5.4(\mathrm{~s})$.

IR (ATR) v/cm ${ }^{-1}=2958,2900,2839,2272,1604,1503,1457$, $1378,1362,1335,1274,1188,1163,1124,1095,1081,1029$, $982,867,802,755,732,710,693,686,661$.

Elem. Anal. calcd. for $\mathrm{C}_{52} \mathrm{H}_{106} \mathrm{~B}_{2} \mathrm{~N}_{4} \mathrm{O}_{4} \mathrm{P}_{8} \mathrm{~W}_{2}$ : C, 41.96; $\mathrm{H}, 7.18$; $N$, 3.76. Found: $C, 42.20 ; \mathrm{H}, 7.40 ; \mathrm{N}, 3.70$.

\section{Conflicts of interest}

The authors declare no conflict of interest. 


\section{Acknowledgements}

A. C. is grateful to the French Ministry of National and Superior Education and Research (MENESR) for a Ph. D. fellowship. CSC is acknowledged for PhD fellowship of D. Z. A. S. acknowledges the European Research Council (ERC) for funding (Grant Agreement 757501). C. Bijani is acknowledge for assistance with additional NMR experiments during the revision process.

\section{Notes and references}

1 (a) S. Kim, F. Loose and P. J. Chirik, Chem. Rev., 2020, 120, 5637-5681; (b) D. Singh, W. R. Buratto, J. F. Torres and L. J. Murray, Chem. Rev., 2020, 120, 5517-5581; (c) Y. Nishibayashi, Ed., Transition Metal-Dinitrogen Complexes: Preparation and Reactivity, Wiley-VCH Verlag $\mathrm{GmbH} \&$ Co. KGaA, Weinheim, Germany, 2019; (d) M. D. Walter, in Advances in Organometallic Chemistry, ed. P. J. Pérez, Academic Press, 2016, vol. 65, pp. 261-377; (e) B. A. MacKay and M. D. Fryzuk, Chem. Rev., 2004, 104, 385-402; (f) S. Gambarotta and J. Scott, Angew. Chem. Int. Ed., 2004, 43, 5298-5308; (g) M. Hidai and Y. Mizobe, Chem. Rev., 1995, 95, 1115-1133; (h) J. Chatt, J. R. Dilworth and R. L. Richards, Chem. Rev., 1978, 78, 589-625.

2 (a) M. J. Chalkley, M. W. Drover and J. C. Peters, Chem. Rev., 2020, 120, 5582-5636; (b) S. L. Foster, S. I. P. Bakovic, R. D. Duda, S. Maheshwari, R. D. Milton, S. D. Minteer, M. J. Janik, J. N. Renner and L. F. Greenlee, Nat. Catal., 2018, 1, 490-500; (c) N. Stucke, B. M. Flöser, T. Weyrich and F. Tuczek, Eur. J. Inorg. Chem., 2018, 2018, 1337-1355; (d) Y. Roux, C. Duboc and M. Gennari, ChemPhysChem, 2017, 18, 2606-2617; (e) Y. Nishibayashi, Ed., Nitrogen Fixation, Springer International Publishing AG, Cham, Switzerland, 2017.

3 (a) G. Ertl, Angew. Chem. Int. Ed., 2008, 47, 3524-3535; (b) R. Schlögl, Angew. Chem. Int. Ed., 2003, 42, 2004-2008; (c) J. R. Jennings, Catalytic Ammonia Synthesis: Fundamentals and Practice, Springer, 1991.

4 (a) A. J. Jasniewski, C. C. Lee, M. W. Ribbe and Y. Hu, Chem. Rev., 2020, 120, 5107-5157; (b) C. Van Stappen, L. Decamps, G. E. Cutsail, R. Bjornsson, J. T. Henthorn, J. A. Birrell and S. DeBeer, Chem. Rev., 2020, 120, 5005-5081; (c) H. L. Rutledge and F. A. Tezcan, Chem. Rev., 2020, 120, 5158-5193; (d) O. Einsle and D. C. Rees, Chem. Rev., 2020, 120, 4969-5004; (e) B. M. Hoffman, D. Lukoyanov, Z.-Y. Yang, D. R. Dean and L. C. Seefeldt, Chem. Rev., 2014, 114, 4041-4062.

5 (a) A. Simonneau, R. Turrel, L. Vendier and M. Etienne, Angew. Chem. Int. Ed., 2017, 56, 12268-12272; (b) A. Coffinet, D. Specklin, L. Vendier, M. Etienne and A. Simonneau, Chem. Eur. J., 2019, 25, 14300-14303.

6 (a) D. J. Parks, R. E. von H. Spence and W. E. Piers, Angew. Chem. Int. Ed. Engl., 1995, 34, 809-811; (b) D. J. Parks, W. E. Piers and G. P. A. Yap, Organometallics, 1998, 17, 5492-5503.

7 (a) A. Rempel, S. K. Mellerup, F. Fantuzzi, A. Herzog, A. Deißenberger, R. Bertermann, B. Engels and H. Braunschweig, Chem. Eur. J., 2020, 26, 16019-16027; (b) H. Ishino, Y. Ishii and M. Hidai, Chem. Lett., 1998, 27, 677-678.

8 Hydroboranes are known catalysts for hydroboration reactions: (a)M. Hoshi and A. Arase, Synth. Commun., 1997, 27, 567-572; (b) P. Eisenberger, A. M. Bailey and C. M. Crudden, J. Am. Chem. Soc., 2012, 134, 17384-17387; (c) A. Prokofjevs, A. Boussonnière, L. Li, H. Bonin, E. Lacôte, D. P. Curran and E. Vedejs, J. Am. Chem. Soc., 2012, 134, 1228112288; (d) M. Fleige, J. Möbus, T. vom Stein, F. Glorius and D. W. Stephan, Chem. Commun., 2016, 52, 10830-10833; (e) Q. Yin, S. Kemper, H. F. T. Klare and M. Oestreich, Chem. Eur. J., 2016, 22, 13840-13844; (f) R. Lawson, L. C. Wilkins and R. L.
Melen, Chem. Eur. J., 2017, 23, 10997-11000; (g) Q. Yin, Y. Soltani, R. L. Melen and M. Oestreich, Organometallics, 2017, 36, 2381-2384; (h) N. W. J. Ang, C. S. Buettner, S. Docherty, A. Bismuto, J. R. Carney, J. H. Docherty, M. J. Cowley and S. P. Thomas, Synthesis, 2018, 50, 803-808; (i) E. Nieto-Sepulveda, A. D. Bage, L. A. Evans, T. A. Hunt, A. G. Leach, S. P. Thomas and G. C. Lloyd-Jones, J. Am. Chem. Soc., 2019, 141, 1860018611.

9 (a) H. C. Brown, N. R. Ayyangar and G. Zweifel, J. Am. Chem. Soc., 1964, 86, 397-403; (b) H. C. Brown, E. Negishi and J. J. Katz, J. Am. Chem. Soc., 1975, 97, 2791-2798.

10 S. Berski, Z. Latajka and A. J. Gordon, New J. Chem., 2011, 35, 89-96.

11 A. Coffinet, A. Simonneau and D. Specklin, in Encyclopedia of Inorganic and Bioinorganic Chemistry, ed. R. A. Scott, WileyVCH Verlag GmbH \& Co. KGaA, 2020, pp. 1-25.

12 P. Pyykkö and M. Atsumi, Chem. Eur. J., 2009, 15, 1277012779.

13 (a) T. Takahashi, T. Kodama, A. Watakabe, Y. Uchida and M. Hidai, J. Am. Chem. Soc., 1983, 105, 1680-1682; (b) H. F. Klein, K. Ellrich and K. Ackermann, J. Chem. Soc. Chem. Commun., 1983, 888-889; (c) K. Takagahara, H. Ishino, Y. Ishii and M. Hidai, Chem. Lett., 1998, 897-898.

14 Traces of $\mathbf{3}$ were detected when monitoring the reaction of 10 and 2 by ${ }^{31} \mathrm{P}\left\{{ }^{1} \mathrm{H}\right\}$ NMR but no quantitative build-up, see ESI.

15 M. Erdmann, C. Rösener, T. Holtrichter-Rößmann, C. G. Daniliuc, R. Fröhlich, W. Uhl, E.-U. Würthwein, G. Kehr and G. Erker, Dalton Trans., 2013, 42, 709-718.

16 H. C. Brown and S. K. Gupta, J. Am. Chem. Soc., 1971, 93, 1816-1818.

17 Z. M. Heiden and A. P. Lathem, Organometallics, 2015, 34, 1818-1827.

18 An experiment allowed us to highlight the similarities of 1 and HBCat as far as the title reaction is concerned: when an equimolar mixture of $\mathbf{2}$ and 9-BBN was treated with a catalytic amount of HBCat, 9 slowly formed (ca. $30 \%$ conversion according to ${ }^{31} \mathrm{P} N M R$ after 10 days at $80^{\circ} \mathrm{C}$ ), indicating that HBCat (or potentially a borane issued after reaction with excess $9-\mathrm{BBN}$ ) can also catalyse the 1,3-B-H bond addition reaction, though less efficiently than 1 (see Fig. S27).

19 A. Abiko, Org. Synth., 2002, 79, 103.

20 H. C. Brown and N. N. Joshi, J. Org. Chem., 1988, 53, 40594062.

21 R. K. Harris, E. D. Becker, S. M. Cabral de Menezes, R. Goodfellow and P. Granger, Pure Appl. Chem., 2001, 73, 17951818. 